\title{
Preparation of carbon molecular sieve membranes from an optimized ionic liquid-regenerated cellulose precursor
}

\author{
Sandra C. Rodrigues ${ }^{\mathrm{a}}$, Márcia Andrade ${ }^{\mathrm{a}}$, Jamie Moffat ${ }^{\mathrm{b}}$, Fernão D. Magalhães ${ }^{\mathrm{a}}$, Adélio Mendes ${ }^{\mathrm{a}, *}$ \\ ${ }^{\text {a } L E P A B E ~-~ F a c u l d a d e ~ d e ~ E n g e n h a r i a, ~ U n i v e r s i d a d e ~ d o ~ P o r t o, ~ R u a ~ D r . ~ R o b e r t o ~ F r i a s, ~ 4200-465 ~ P o r t o, ~ P o r t u g a l ~}$ \\ ${ }^{\mathrm{b}}$ Innovia Films Ltd., Wigton, Cumbria CA7 9-BG, UK
}

\section{A R T I C L E I N F O}

\section{Keywords:}

Carbon molecular sieve membrane

Water vapor stability

Gas separation

Ionic liquid

Regenerated cellulose

\begin{abstract}
A B S T R A C T
Novel carbon molecular sieve membranes with high separation performance and stability in the presence of humidified streams were prepared from an optimized ionic liquid-regenerated cellulose precursor, in a single carbonization step. Membranes prepared at two different carbonization end temperatures $\left(550^{\circ} \mathrm{C}\right.$ and $\left.600{ }^{\circ} \mathrm{C}\right)$ were analyzed through scanning electron microscopy, thermogravimetric analysis, Fourier transform infrared spectroscopy, carbon dioxide adsorption and permeation experiments. The prepared membranes exhibited uniform thickness of approximately $20 \mu \mathrm{m}$ and a well-developed microporous structure. The permeation performance of these carbon molecular sieve membranes was above the Robeson upper bound curve for polymeric membranes. In particular, the membrane prepared at $550{ }^{\circ} \mathrm{C}$ end temperature exhibited permeability to oxygen of 5.16 barrer and $\mathrm{O}_{2} / \mathrm{N}_{2}$ ideal selectivity of 32.3 and permeability to helium of 126 barrer and He/ $\mathrm{N}_{2}$ ideal selectivity of 788; besides, permeation experiments performed in the presence of $c a$. $80 \%$ relative humidity showed that humidity does not originate pore blockage. These results open the door for the preparation of tailor made precursors that originate carbon molecular sieve membranes with extraordinary separation performances, mechanical resistance and stability.
\end{abstract}

\section{Introduction}

Over the past few decades, membrane processes for gas separation have improved considerably. Compared to conventional separation techniques, membrane based gas separation is more attractive because of its high adaptability, high reliability, low energy consumption and low capital cost, operation and maintenance, which makes it a more energy-saving and environmental friendly technology [1-4]. On the other hand, carbon molecular sieve membranes (CMSM) have been considered promising candidates for gas separation due to their high corrosion resistance, high thermal stability and excellent permeabilities/permselectivities when compared to polymeric membranes [5-7]. CMSM are prepared from the carbonization of a polymeric precursor under controlled conditions (atmosphere and temperature history); after the carbonization step, CMSM display a highly aromatic structure comprising disordered $\mathrm{sp}^{2}$ hybridized carbon sheets packed imperfectly. Pores are formed from packing imperfections between microcrystalline regions in the material [8]; the CMSM structure is turbostratic and described as "slit-like" with a bimodal pore size distribution with micropores connecting ultramicropores [8,9]. Micropores provide sorption sites while ultramicropores (called constrictions) enable molecular sieving, making CMSM both highly permeable and highly selective - a distinct characteristic of these materials [10-12]. Despite all attractive characteristics displayed by CMSM, they display significant challenges related to their stability when exposed to specific environments [13-15]. In the presence of humidity, water initially adsorbs onto CMSM hydrophilic functional groups and once the first water molecule is adsorbed, adsorbate-adsorbate interactions promote the adsorption of further molecules through hydrogen bonding, originating clusters of several water molecules. The resulting cluster has enough dispersion energy to be released from the hydrophilic group, rolling up until blocking a constriction of the pore network [15]. Consequently, the membrane permeability decreases abruptly, making the carbon membrane useless; this aging effect has seriously limited the commercialization of CMSM.

Up to now, many polymeric precursors have been extensively studied to obtain CMSM with excellent separation performances and stability. These precursors include polyimides [16-20], polyacrylonitrile [21], poly(furfuryl alcohol) [22,23], phenolic resins [24-28], resorcinol-formaldehyde resin [29-32] and cellulose [16,33-35]. Recently, our group applied for a patent of a process for obtaining, in a single carbonization step, CMSM that display no pore blockage effect in

\footnotetext{
* Corresponding author.

E-mail address: mendes@fe.up.pt (A. Mendes).
} 
the presence of water vapor and display very high ideal permselectivities for several relevant industrial gas mixtures [36]; these novel carbon molecular sieve membranes were prepared from a commercial cellophane precursor - regenerated cellulose produced by the viscose process. Nevertheless, the obtained CMSM displayed low permeabilities to permanent gases and it was not possible to prepare a tailor made precursor.

Cellulose makes an excellent precursor material for the preparation of CMSM due to its considerable carbon yield, biodegradability, hidrophilicity and low-cost [37-39]. The chemical structure of cellulose consists in anhydroglucose linearly linked by $(1,4)-\beta$-D-glucosidic bounds, and the number of molecular glucose units defines its degree of polymerization $[37,40]$. However, the strong inter and intra hydrogen bonds between cellulose macromolecular chains make it difficult to be dissolved in general solvents $[39,41]$. The viscose technology uses a metastable solution of cellulose xanthogenate with hazardous byproducts like heavy metals and hydrogen sulfide [42-44]; moreover, it generates two kilograms of waste per kilogram of cellulose obtained $[45,46]$. Other conventional cellulose solvent systems have numerous drawbacks such as limited dissolution capability, toxicity, high cost, uncontrollable side reactions, instability during cellulose processing and/or derivatization [38,47] and negative environmental impacts [48].

Ionic liquids (ILs), a group of salts with poorly coordinated ions and consequently low melting points, represent a promising alternative to existing cellulose-dissolving solvents. ILs have been proposed as environmentally "green solvents"; they present a wide range of melting temperatures $\left(-40-400^{\circ} \mathrm{C}\right)$, have low vapor pressure, excellent dissolution ability, high thermal stability (up to $400{ }^{\circ} \mathrm{C}$ ), are noninflammable, chemical stability, and ease of recyclability [40,49-51]. ILs are made up of separate cationic and anionic species, but unlike common salts, they have a low tendency to crystallize due to their bulky and asymmetrical cation structure [50]; their properties for a specific need can be tuned combining suitable cations and anions [52]. Moreover, ionic liquids give the opportunity to produce tailor made regenerated cellulose precursor films that allow the preparation of carbon membranes with a high separation performance, mechanical resistance and stability.

In this work, we report the preparation and characterization of regenerated cellulose-based CMSM using an ionic liquid (1-ethyl-3-methyl imidazolium acetate) (EMIMAc) to dissolve cellulose and a spin coating method to cast the precursor membrane. EMIMAc is liquid at room temperature, has high dissolving power even in the presence of $10 \mathrm{wt} \%$ of water, relatively low viscosity when compared to other ionic liquids, low toxicity and high hydrogen bond acceptor abilities. Hydrogen bond acceptor sites in the anion structure and lack of hydrogen bond donors in the ionic liquid cation favor the dissolution of cellulose. The acetate anion in 1-ethyl-3-methyl imidazolium acetate can form hydrogen bonds with hydroxyl protons of cellulose (Fig. 1).

To the best of the authors' knowledge, this is the first time that regenerated cellulose films produced through an ionic liquid process are studied for preparation of CMSM. Defect-free CMSM were successfully and reproducibly prepared at two different carbonization end temperatures, $550{ }^{\circ} \mathrm{C}$ and $600{ }^{\circ} \mathrm{C}$.

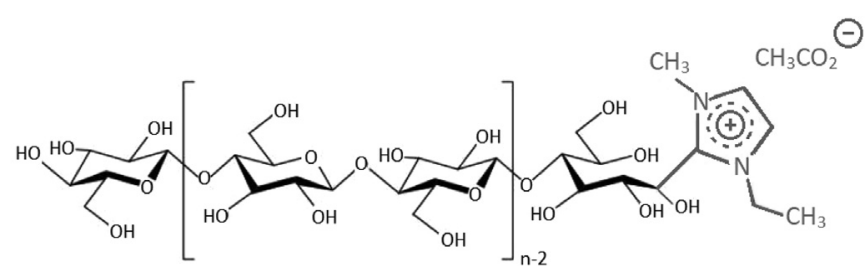

Fig. 1. Schematic representation of cellulose and 1-ethyl-3-methylimidazolium acetate covalent binding (adapted from [42]).

\section{Experimental}

\subsection{Materials}

Wood pulp (cellulose) was provided by Innovia Films Ltd., displaying a degree of polymerization (DP) of 450. The ionic liquid 1ethyl-3-methylimidazolium acetate (EMIMAc) and propylene glycol $(\geq 99.5 \%$ ), used as plasticizer, were supplied by Sigma-Aldrich. Dimethyl sulfoxide (DMSO) was purchased from Fisher Scientific. The permanent gases were supplied by Air Liquid (99.999\% pure).

\subsection{Preparation of regenerated cellulose precursor membranes}

Wood pulp was dispersed in DMSO and EMIMAc (70:30 wt\% of DMSO: EMIMAc) to prepare a $9.2 \mathrm{wt} \%$ cellulose solution. The mixture was heated at $90^{\circ} \mathrm{C}$ under magnetic stirring until cellulose was completely dissolved. After dissolution, the resultant brownish solution was filtered with a wire mesh and placed in a vacuum oven at $40{ }^{\circ} \mathrm{C}$ for degassing during $2 \mathrm{~h}$. The obtained homogeneous solution was subsequently spin coated on rectangular glass plates with a spin-coater (POLOS $^{\mathrm{TM}}$, SPIN150i) at a spinning speed of $2000 \mathrm{rpm}$, spin acceleration of $1000 \mathrm{rpm} / \mathrm{s}$ and a spinning time of $10 \mathrm{~s}$. After coating, the films were immediately coagulated in distilled water $\left(25^{\circ} \mathrm{C}\right)$ to obtain a transparent regenerated cellulose film. The film was then intensely washed with distilled water for $60 \mathrm{~min}$ to remove the excess of ionic liquid. After that, the washed film was dipped in a softener bath containing $5 \mathrm{wt} \%$ of propylene glycol for $1 \mathrm{~min}$ and then dried in an oven at $100{ }^{\circ} \mathrm{C}$ for 10 min Fig. 2 summarizes the preparation steps of the regenerated cellulose precursor membranes.

\subsection{Preparation of regenerated cellulose-based carbon molecular sieve membranes}

Previous to carbonization, the precursor membranes were cut in disks with $48 \mathrm{~mm}$ diameter. The carbonization was then accomplished in a quartz tube $(80 \mathrm{~mm}$ in diameter and $1.5 \mathrm{~m}$ in length) inside a tubular horizontal Termolab TH furnace. To guarantee temperature homogeneity along the quartz tube, the furnace has three separating heating elements controlled by three PID control heating parameters. Fig. 3 gives a schematic overview of the setup for carbonization.

The carbonization was performed under $\mathrm{N}_{2}$ atmosphere, with flowrate of $170 \mathrm{ml} \mathrm{min}^{-1}$ and a heating rate of $0.5^{\circ} \mathrm{C} \mathrm{min}{ }^{-1}$. Fig. 4 shows the heating history used to prepare the carbon molecular sieve membranes from regenerated cellulose films. The temperature history comprehends essentially slow heating rates with several dwells of $30 \mathrm{~min}$ to avoid a quick release of residual solvents/volatile matter that could damage the carbon matrix, causing cracks/defects. Two end temperatures were considered, $550^{\circ} \mathrm{C}$ (CMSM 550) and $600{ }^{\circ} \mathrm{C}$ (CMSM $600)$; after the end temperature was reached, the system was allowed to cool naturally until room temperature, and the flat carbon molecular sieve membranes were finally removed from the carbonization furnace.

\subsection{Scanning electron microscopy}

Micrographs of the regenerated cellulose precursor membrane and derived CMSM have been taken by scanning electron microscopy (SEM) using a high resolution scanning electron microscope JEOL JSM 6301F/ Oxford INCA Energy 350 with x-ray microanalysis. All the samples were previously sputtered with gold/palladium using a SPI Module Sputter Coater equipment to allow better conductivity for SEM.

\subsection{Thermogravimetric analysis}

Thermogravimetric analysis (TGA) was carried out in a Netzsch TG 209 F1Iris thermogravimetric balance with a resolution of $0.1 \mu \mathrm{m}$. The heating procedure [34] consisted on first rise the temperature from 


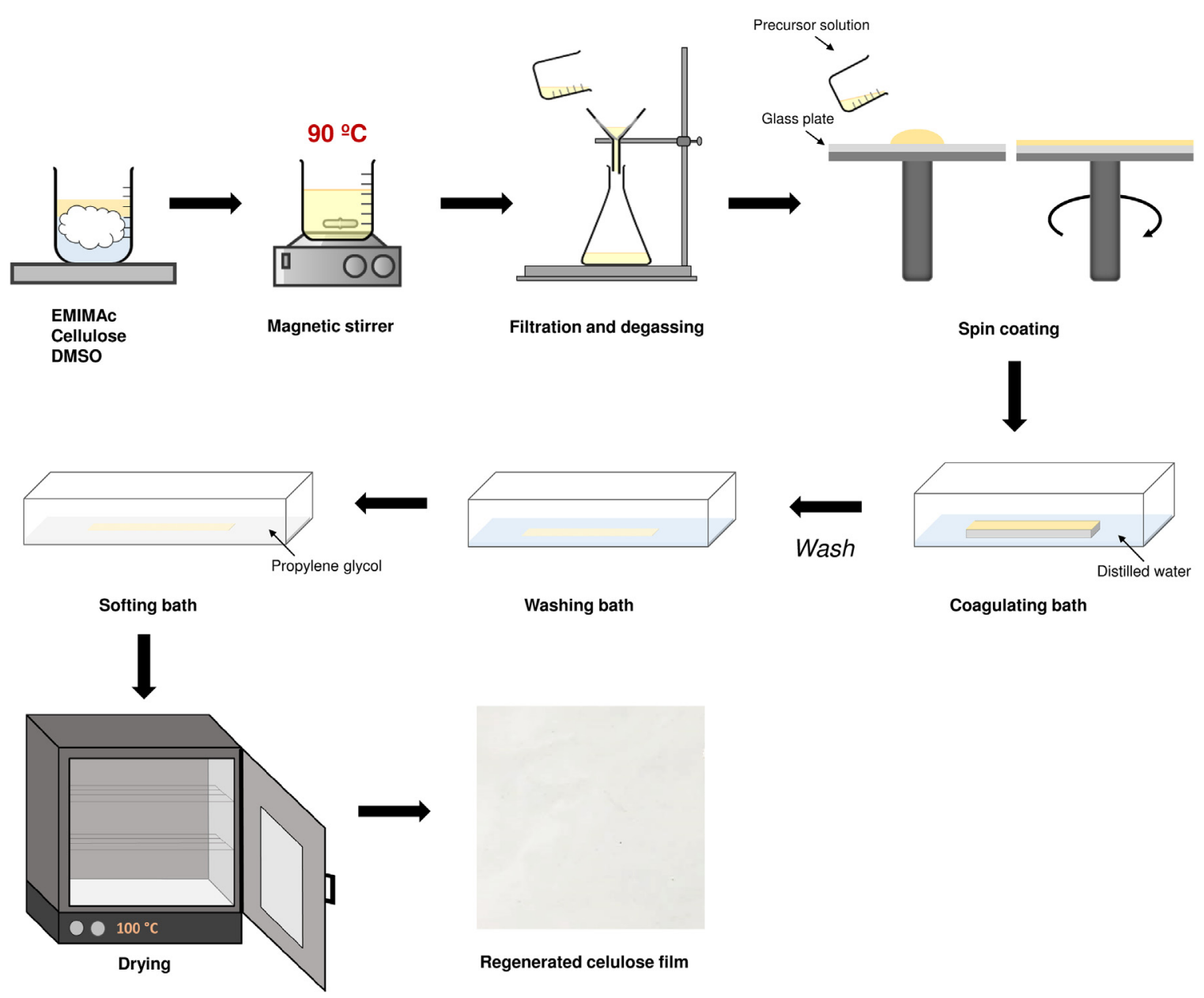

Fig. 2. Preparation steps of the regenerated cellulose precursor membranes.

room temperature to $110^{\circ} \mathrm{C}$ at $10^{\circ} \mathrm{C} \mathrm{min}^{-1}$, under nitrogen atmosphere, with two dwells at $50^{\circ} \mathrm{C}$ (for $10 \mathrm{~min}$ ) and $110^{\circ} \mathrm{C}$ (for $7 \mathrm{~min}$ ); subsequently, temperature rise from $110^{\circ} \mathrm{C}$ to $950{ }^{\circ} \mathrm{C}$ with a dwell at $950^{\circ} \mathrm{C}$ (for $9 \mathrm{~min}$ ) and finally the sample was kept at $950^{\circ} \mathrm{C}$ for more 11 min under oxygen atmosphere. Proximate analysis was performed to determine the percentage of moisture, volatile matter, carbon yield and ashes content of the precursor material [53]: after the first dwell at $110^{\circ} \mathrm{C}$, humidity is removed; up to the second dwell, volatile matter is released and after the last dwell at $950^{\circ} \mathrm{C}$ (under oxygen), all the fixed carbon is burned, leaving only ashes (if present).

\subsection{Fourier transform infrared spectroscopy (FTIR)}

The infrared spectra of the precursor and derived CMSM were recorded using a VERTEX 70 FTIR spectrometer (BRUKER) in transmittance mode with a high sensitivity DLaTGS detector at room temperature. Samples were measured in ATR mode, with a A225/Q PLATINUM
ATR Diamond crystal with single refection accessory. The spectra were recorded from 4000 to $500 \mathrm{~cm}^{-1}$ with a resolution of $4 \mathrm{~cm}^{-1}$.

\subsection{Pore size distribution}

The pore size distribution (PSD) of the CMSM was obtained based on the adsorption equilibrium isotherm of carbon dioxide at $0{ }^{\circ} \mathrm{C} \mathrm{ob}$ tained by the volumetric method. This method is based on pressure variation of the gas after an expansion; assuming for the system an ideal gas behavior and knowing the pressure decrease, the concentration of the adsorbed solute can be determined [54,55]. The apparatus used to perform these experiments is described elsewhere [55].

\subsection{Permeation experiments}

Prior to permeation experiments, the CMSM were glued to steel Orings with an epoxy glue (Araldite Standard); the glue was also applied

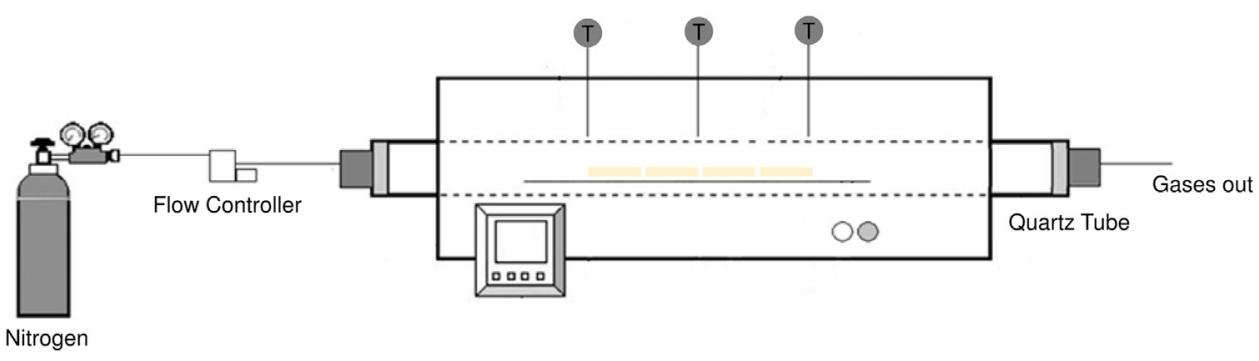

Fig. 3. Carbonization setup used to prepare the regenerated cellulose-based CMSM. 


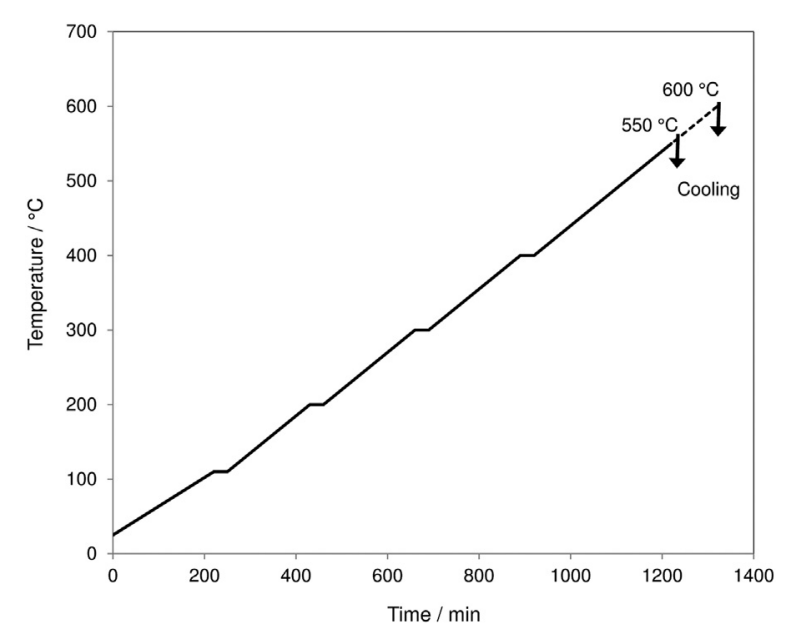

Fig. 4. Carbonization protocol to prepare the regenerated cellulose-based CMSM.

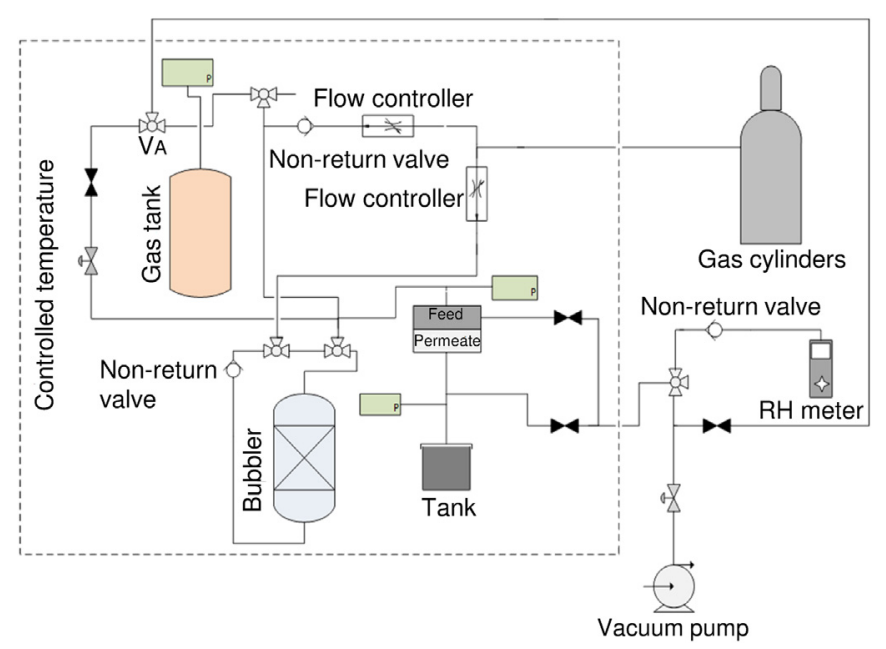

Fig. 5. Scheme of the experimental setup for gas permeation experiments.

along the interface of the steel O-ring and the carbon membrane, as described elsewhere [34]. A sintered metal disc covered with a filter paper was used as support for the film in the test cell. Single gases were tested at $25^{\circ} \mathrm{C}$, where the feed pressure was 1 bar and the permeate pressure was $\mathrm{ca}$. 0.03 bar. The tests were performed in a standard pressure-rise setup with LabView ${ }^{\circledast}$ data logging. As shown in Fig. 5, the system included the membrane cell connected to a tank with a calibrated volume (at the permeate side) and to a gas tank (at the feed side). The feed gas can either be used dry or humidified; for experiments with an humidified gas stream, part of the gas stream from the cylinder was bubbled in a distilled water bubbler, balanced with dry gas for producing the desired humidity level, and fed to the membrane cell. The relative humidity was checked for every run with a $\mathrm{RH}$ meter (Vaisala DMP74b) at an exit port.

The permeability of the CMSM towards a pure component $i, L_{i}$, was determined accordingly to:

$L_{i}=\frac{F_{i}}{\Delta P_{i} / \delta}$

where $F_{i}$ is the flux of species $i, \Delta P_{i}$ the partial pressure difference of species $i$ between the two sides of the membrane and $\delta$ the membrane thickness (determined by scanning electron microscopy). The membrane permeability to pure component $i$ was computed from the experimental data as follows:

$L_{i}=\frac{\delta V_{p} v_{M} \Delta P_{p}}{R T t A\left(P_{f}-P_{p}\right)}$

where $V_{p}$ is the volume of the permeate tank, $v_{M}$ is the molar volume of the gas at normal conditions, $R$ is the gas constant, $T$ is the absolute temperature, $t$ is the time, $A$ is the effective area of the flat carbon membrane and $P_{f}$ and $P_{p}$ are the feed pressure and permeate pressure, respectively; $\Delta P_{p}$ is the permeate pressure increment for the time $t$. Barrer is the most frequently used unit to express permeability, where 1 barrer $=3.39 \times 10^{-16} \mathrm{~mol} \mathrm{~m} \mathrm{~m}{ }^{-2} \mathrm{~s}^{-1} \mathrm{~Pa}^{-1}$. The ratio of two gases permeability coefficients is the ideal selectivity [56]:

$\alpha_{i, j}=\frac{L_{i}}{L_{j}}$

\section{Results and discussion}

\subsection{Preparation of regenerated cellulose-based CMSM}

The prepared regenerated cellulose-based CMSM are identified in Table 1. The precursor disks shrank during the carbonization step and the shrinkage fraction $(\mathrm{SH})$ of each CMSM was determined as follows:

$S H=\frac{D_{\text {before }}-D_{\text {after }}}{D_{\text {before }}} \times 100$

where $D_{\text {before }}$ is the membrane diameter before carbonization and $D_{\text {after }}$ is the membrane diameter after the carbonization step.

From Table 1, it can be observed that shrinkage increased with the carbonization end temperature. Similarly, the increase in the carbonization end temperature led to a decrease in the membrane thickness $(\delta$, measured by SEM). Fig. 6 shows a membrane before and after carbonization.

\subsection{Scanning electron microscopy}

The structure of the membranes was examined by SEM. In a previous study, the research team prepared CMSM from commercial cellophane paper (a regenerated cellulose film produced by the viscose process) $[36,57]$. For the first time carbon molecular sieve membranes with stability to water vapor and oxygen were prepared. However, these cellophane-based CMSM displayed rather low permeabilities. Moreover, the viscose technology uses a metastable solution of cellulose xanthogenate with hazardous byproducts and viscose precursor solution degrades over a period of $c a$. 3 days; consequently, it is very difficult to produce tailor made membrane precursors. The preparation of cellulosic solutions using the ionic liquid process gives the opportunity for preparing tailor made precursors that originate stable carbon

Table 1

Identification of carbon membranes derived from regenerated cellulose.

\begin{tabular}{|c|c|c|c|c|c|c|c|}
\hline \multirow[t]{2}{*}{ Sample } & \multicolumn{2}{|c|}{ Before carbonization } & \multirow[t]{2}{*}{ Carbonization temperature $\left({ }^{\circ} \mathrm{C}\right)$} & \multicolumn{3}{|c|}{ After carbonization } & \multirow[t]{2}{*}{ Physical properties } \\
\hline & $D(\mathrm{~mm})$ & $\delta(\mu \mathrm{m})$ & & $D(\mathrm{~mm})$ & SH (\%) & $\delta(\mu \mathrm{m})$ & \\
\hline Precursor & 48 & 35.6 & - & - & - & - & Transparent, flexible \\
\hline CMSM 550 & 48 & 35.6 & 550 & 33 & 31 & 20.1 & Black, bright, brittle \\
\hline CMSM 600 & 48 & 35.6 & 600 & 28 & 42 & 18.0 & Black, bright, brittle \\
\hline
\end{tabular}



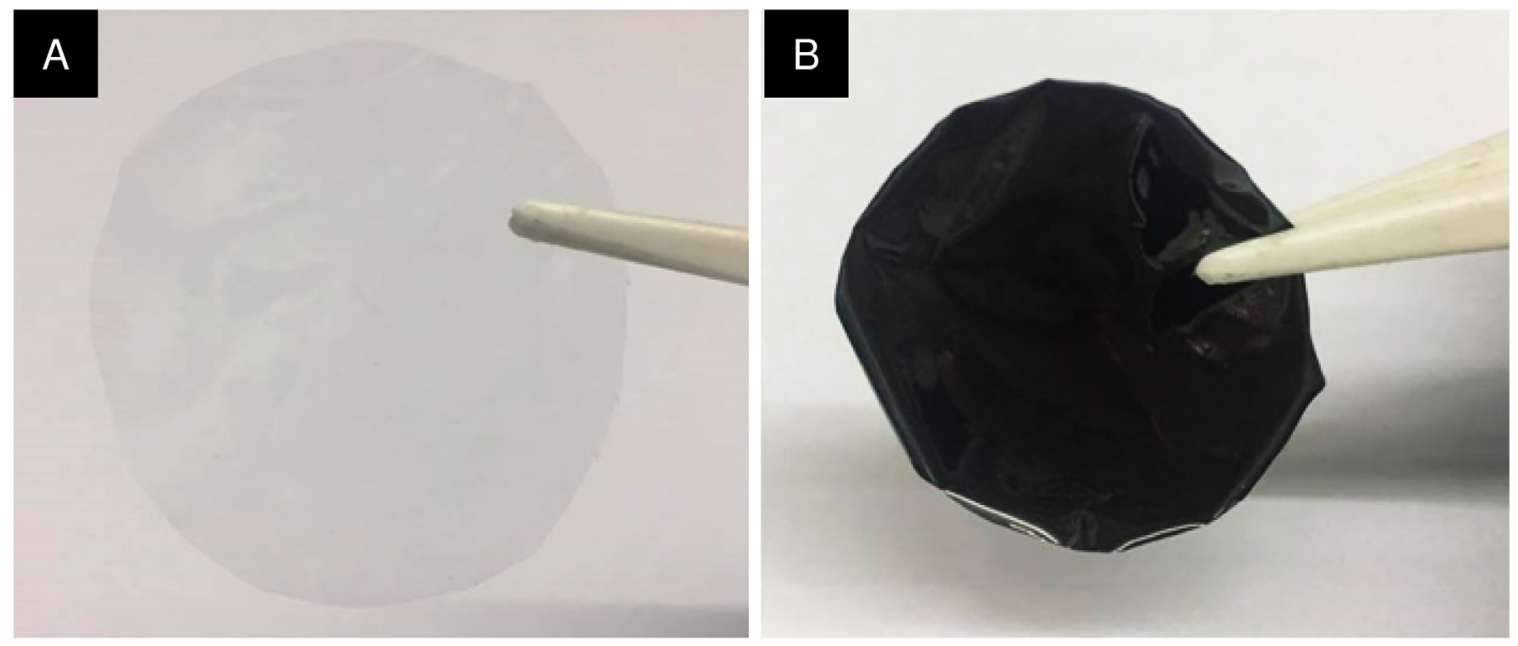

Fig. 6. Regenerated cellulose membrane before (A) and after (B) carbonization.

molecular sieve membranes with adjustable properties depending on the final application.

Fig. 7 shows scanning electron micrographs of surface and crosssectional views of a CMSM prepared in this work and a cellophane- based CMSM, both carbonized at $550^{\circ} \mathrm{C}$.

The surface of the sample prepared in this work is very smooth, with no apparent defects (Fig. 7-A) indicating that spin coating is an effective technique for casting the precursor membrane. Microspheres (also
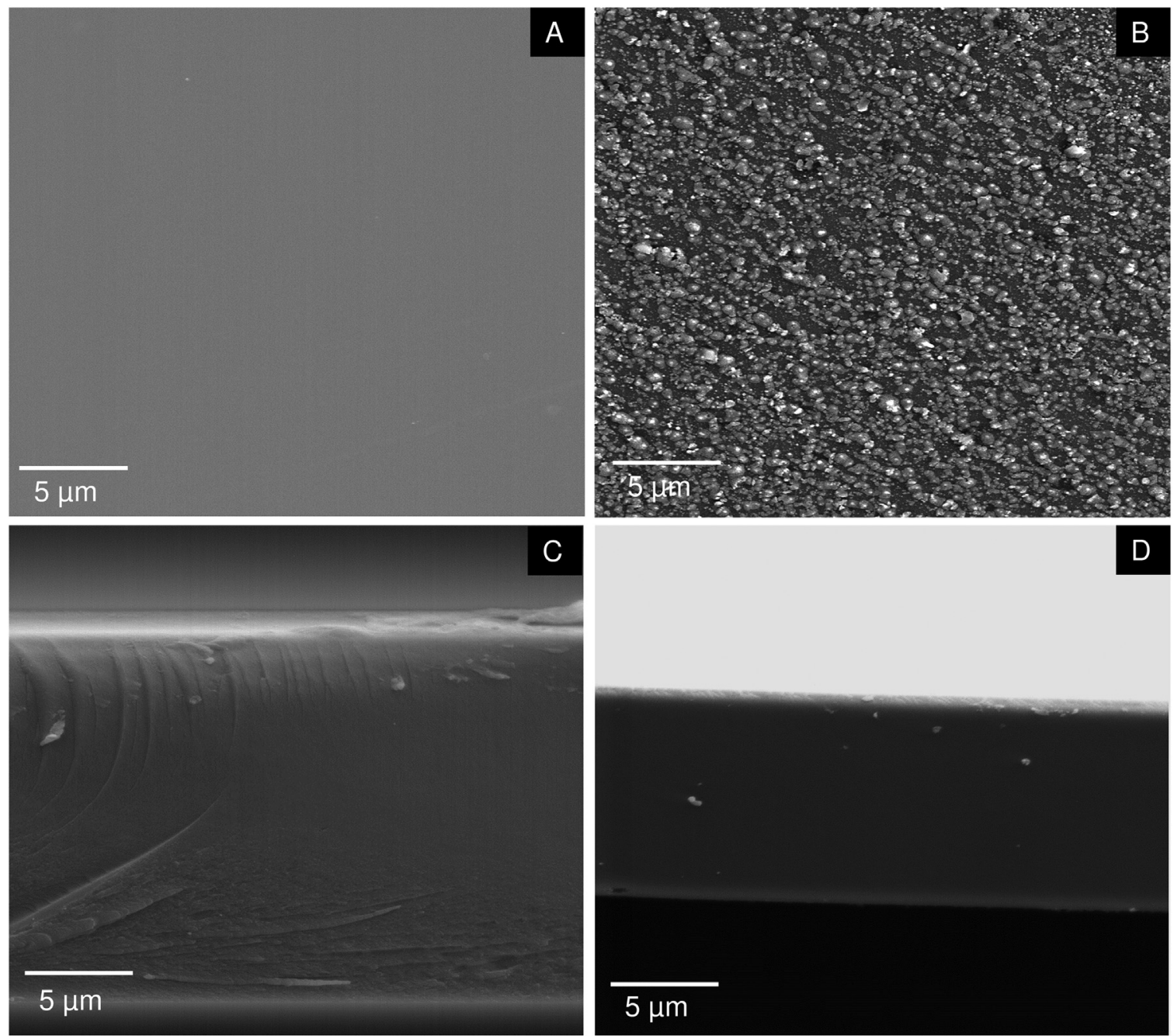

Ionic liquid process

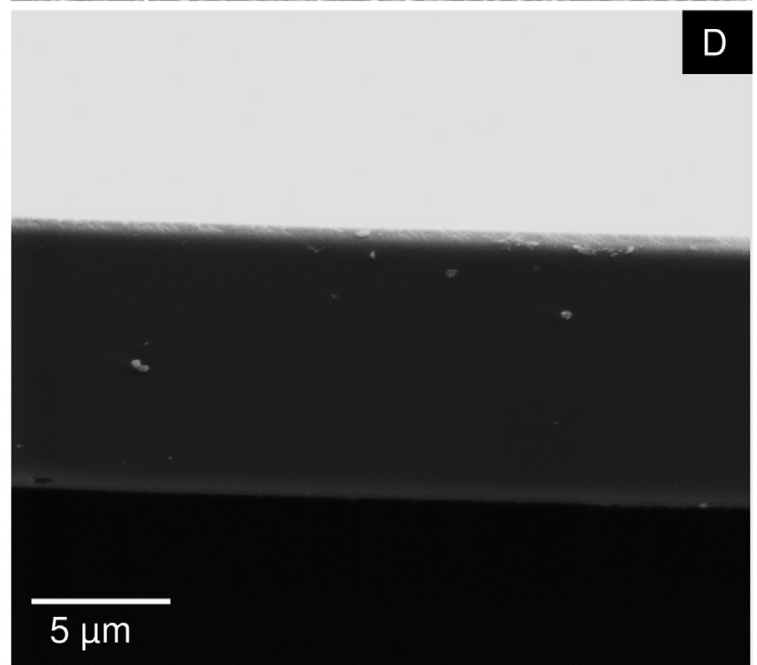

Viscose process

Fig. 7. (A), (B) Surface SEM and (C), (D) cross-sectional images of CMSM obtained from regenerated cellulose films prepared through two different processes: ionic liquid and viscose. Magnification: $\times 5000$. Carbonization end temperature: $550{ }^{\circ} \mathrm{C}$. 


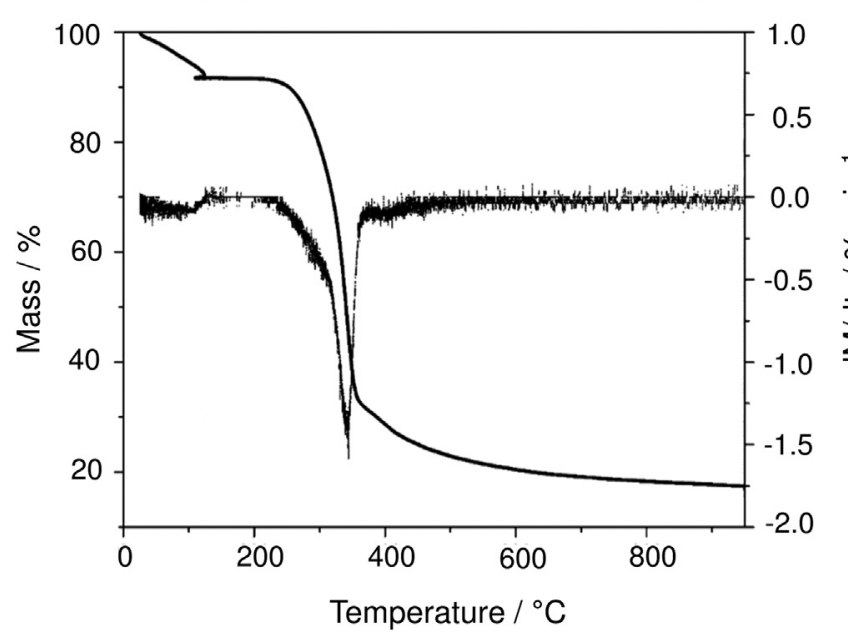

Fig. 8. Thermogravimetric plot and correspondent derivative curve of the regenerated cellulose precursor.

called "condensed benzene rings") [36,58] were observed on the surface of cellophane-based CMSM (Fig. 7-B) [57] but they were not observed on the surface of CMSM prepared through the ionic liquid process (Fig. 7-A).

\subsection{Thermogravimetric analysis}

Thermogravimetric analysis was used to assess the thermal decomposition kinetics and stability of precursor in inert atmosphere. TGA was performed on the dry regenerated cellulose film used to prepare the CMSM. The characteristic curve was obtained under $\mathrm{N}_{2}$ atmosphere and is plotted together with the correspondent mass loss derivative curve in Fig. 8. Up to $100{ }^{\circ} \mathrm{C}$, the first derivative of mass loss curve shows a negative peak related with release of humidity present in the sample. The strong peak around $350{ }^{\circ} \mathrm{C}$ corresponds to the larger mass loss and indicates the degradation of the polymer [59] - an abrupt weight loss indicates the onset of the pore network formation [60]. A minute weight loss is observed at $c a .415^{\circ} \mathrm{C}$ and the mass still decreasing behind this temperature until $950{ }^{\circ} \mathrm{C}$, but at a much slower rate; at $950{ }^{\circ} \mathrm{C}$ the total weight loss was approximately $83 \%$. The regenerated cellulose precursor showed a higher weight loss and at lower temperatures when compared to other polymer precursors commonly used in the preparation of CMSM $[24,26,29,60]$.

Proximate analysis was also performed to determine humidity, volatile matter, fixed carbon and ashes content. Table 2 offers a summary of the results obtained. It was concluded that regenerated cellulose precursor is ash free, presenting $c a .75 \mathrm{wt} \%$ of volatile matter and $c a$. $17 \mathrm{wt} \%$ of fixed carbon.

\subsection{Fourier transform infrared spectroscopy}

The chemical structure of the samples was investigated by Fourier transform infrared spectroscopy. Fig. 9 shows FTIR spectra of the precursor film and derived carbon membranes prepared at $550{ }^{\circ} \mathrm{C}$ and $600^{\circ} \mathrm{C}$ carbonization end temperature. Band assignments for Fig. 9 are summarized in Table 3.

Table 2

Proximate analysis (dry basis) of the regenerated cellulose precursor.

\begin{tabular}{llll}
\hline Proximate analysis $(\mathrm{wt} \%)$ & & \\
\hline Humidity & Volatile matter & Carbon yield & Ashes \\
\hline $\mathbf{8}$ & 75 & 17 & 0 \\
\hline
\end{tabular}

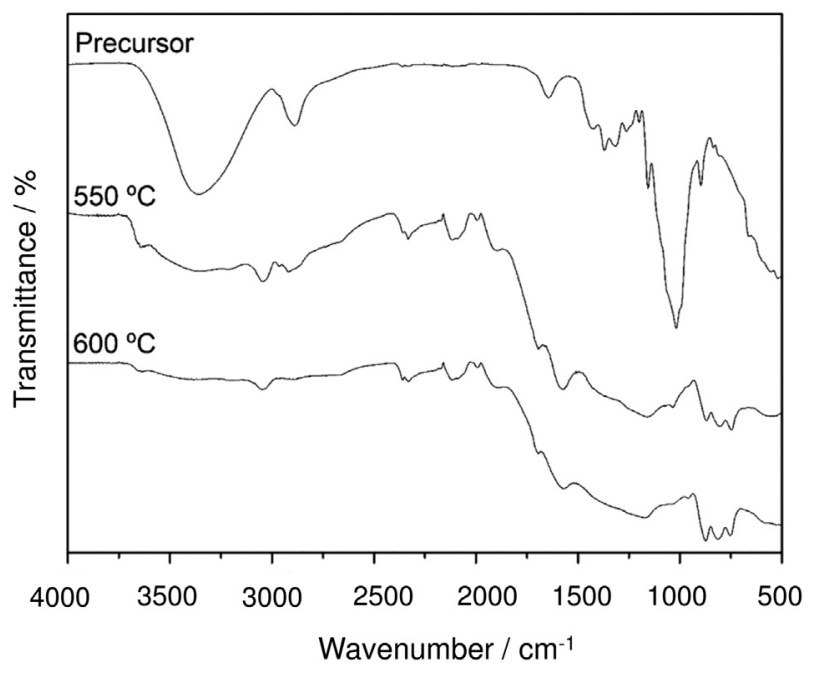

Fig. 9. FTIR spectra of the regenerated cellulose precursor and derived CMSM.

Table 3

FTIR spectra bands assignments.

\begin{tabular}{|c|c|c|}
\hline Wavenumber $\left(\mathrm{cm}^{-1}\right)$ & Functional group & Assignment \\
\hline $3637,3354,3351$ & $-\mathrm{OH}$ & OH stretching \\
\hline 3047 & $=\mathrm{CH}$ & $=\mathrm{C}-\mathrm{H}$ stretching \\
\hline $2965,2919,2887$ & $-\mathrm{CH}_{3}$ and $-\mathrm{CH}_{2}^{-}$ & Aliphatic C-H stretching \\
\hline 2171 & $-\mathrm{N} \equiv \mathrm{C}$ & $\mathrm{N} \equiv \mathrm{C}$ stretching \\
\hline 1985,1895 & Substituted benzene ring & $\begin{array}{l}\text { Several bands from } \\
\text { overtones and } \\
\text { combinations }\end{array}$ \\
\hline 1693 & $\mathrm{C}=\mathrm{O}$ & $\mathrm{C}=\mathrm{O}$ stretching \\
\hline 1643 & $\mathrm{C}=\mathrm{C}$ & $\mathrm{C}=\mathrm{C}$ stretching \\
\hline 1574 & $\mathrm{COO}^{-}$ & $\begin{array}{l}\mathrm{COO}^{-} \text {antisymmetric } \\
\text { stretching }\end{array}$ \\
\hline 1423 & $\mathrm{CH}_{2}$ & $\mathrm{CH}_{2}$ bending \\
\hline $1261,1199,1159,1156,897$ & $\mathrm{C}-\mathrm{O}-\mathrm{C}$ & C-O-C stretching \\
\hline 1034,1018 & $\mathrm{C}-\mathrm{OH}$ & C-O stretching \\
\hline $870,802,746$ & $\begin{array}{l}\text { 1,2,4-Trisubstituted } \\
\text { benzenes; } o \text { - } \\
\text { Disubstituted benzenes }\end{array}$ & $\begin{array}{l}\text { Aromatic C-H out-of- } \\
\text { plane bending }\end{array}$ \\
\hline
\end{tabular}

The precursor spectra show a broad band at $3351 \mathrm{~cm}^{-1}$ which is ascribed to the $\mathrm{O}-\mathrm{H}$ stretching vibrations in hydroxyl or carboxyl groups [61]. The precursor possesses aliphatic structures as it can be deduced from the band at $2887 \mathrm{~cm}^{-1}$, which corresponds to stretching vibrations of aliphatic C-H $[61,62]$. The band at about $1643 \mathrm{~cm}^{-1}$ can be assigned to $C=C$ stretching vibrations and at $1423 \mathrm{~cm}^{-1}$ is attributed to $\mathrm{CH}_{2}$ bending vibrations [63]; the bands at $1261 \mathrm{~cm}^{-1}, 1199 \mathrm{~cm}^{-1}$ and $1156 \mathrm{~cm}^{-1}$ correspond at C-O-C antisymmetric stretching vibrations and the peak at $1018 \mathrm{~cm}^{-1}$ is assigned to C-O stretching vibrations [64] (C-OH group of secondary alcohols existing in the cellulose chain backbone). The peak detected at $897 \mathrm{~cm}^{-1}$ is characteristic of $\beta-(1,4)$ glycosidic linkages between glucose units (C-O-C stretching vibrations) [63].

Regarding the CMSM, the spectra of the samples prepared at the two different carbonization end temperatures are similar. However, band intensities are weaker in CMSM obtained at $600^{\circ} \mathrm{C}$ than those prepared at $550^{\circ} \mathrm{C}$; this implies that the degree of carbonization in CMSM increases with the carbonization end temperature. Absorption bands at $3637 \mathrm{~cm}^{-1}$ and $3354 \mathrm{~cm}^{-1}$, characteristic of O-H stretching vibrations in hydroxyl or carbonyl groups, were observed [61]; at $3047 \mathrm{~cm}^{-1}$ a band ascribed to $=\mathrm{C}-\mathrm{H}$ stretching was also identified [64]. The peaks at $2965 \mathrm{~cm}^{-1}$ and $2919 \mathrm{~cm}^{-1}$ are related to stretching vibrations of aliphatic $\mathrm{C}-\mathrm{H}\left(\mathrm{CH}_{3}\right.$ and $\mathrm{CH}_{2}$ groups, respectively) [61,62,64]; however, it was observed that for samples carbonized at $600^{\circ} \mathrm{C}$ these two bands disappeared. The band identified at $2171 \mathrm{~cm}^{-1}$, for both samples, is 

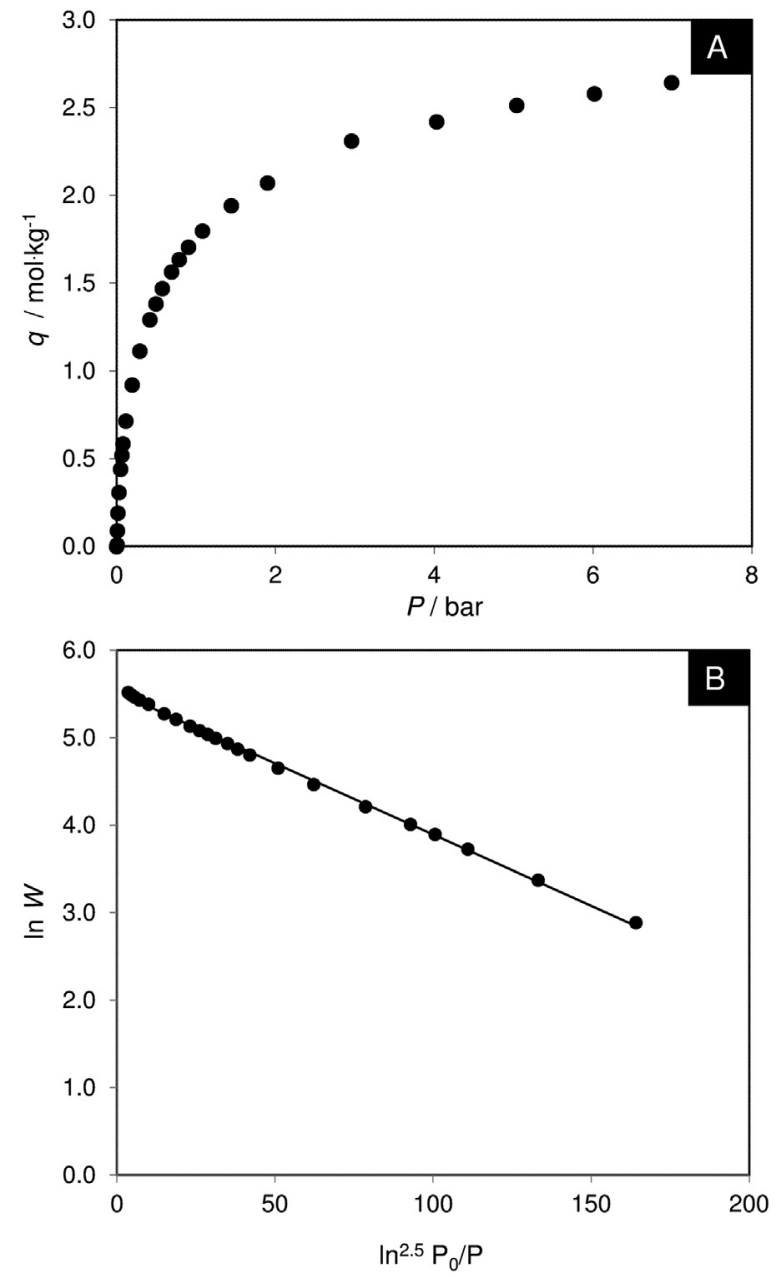

Fig. 10. (A) Adsorption equilibrium isotherm of carbon dioxide at $0{ }^{\circ} \mathrm{C}$ and (B) carbon dioxide characteristic curve (points-experimental data; solid line - DA fitting). Carbonization end temperature: $550{ }^{\circ} \mathrm{C}$.

ascribed to $\mathrm{N} \equiv \mathrm{C}$ stretching vibrations [64]; moreover, two bands characteristic of substituted benzene rings were detected at $1995 \mathrm{~cm}^{-1}$ and $1895 \mathrm{~cm}^{-1}$ [64]. The band at about $1693 \mathrm{~cm}^{-1}$ can be assigned to $\mathrm{C}=\mathrm{O}$ stretching vibrations corresponding to carbonyl, quinone, ester or carboxyl [65]; the band at about $1574 \mathrm{~cm}^{-1}$ can be assigned to $\mathrm{COO}^{-}$ antisymmetric stretching [64], at $1159 \mathrm{~cm}^{-1}$ is attributed to C-O-C antisymmetric stretching vibrations and at $1034 \mathrm{~cm}^{-1}$ is assigned to C$O$ stretching vibrations [65]. The bands in the $870-746 \mathrm{~cm}^{-1}$ region are assigned to aromatic C-H out-of-plane bending vibrations [66].

\subsection{Pore size distribution}

In the present study, the microporosity of the CMSM was assessed based on the adsorption equilibrium isotherm of carbon dioxide at $0{ }^{\circ} \mathrm{C}$; carbon dioxide based pore size distribution is able to describe the CMSM porosity below to the size of $\mathrm{CO}_{2}$ molecule. Fig. 10 shows the adsorption equilibrium isotherm of carbon dioxide at $0{ }^{\circ} \mathrm{C}$ (Fig. 10-A) and the carbon dioxide characteristic curve (Fig. 10-B) for the sample carbonized at $550^{\circ} \mathrm{C}$, as an example. The Dubinin-Astakhov equation was used to fit the experimental data, and to obtain the micropore volume $\left(W_{0}\right)$ and the characteristic energy of adsorption $\left(E_{0}\right)[29,67]$. Table 4 summarizes the obtained structural parameters for each carbon membrane.

The obtained micropore volume for CMSM 550 is typical for carbon molecular sieves; for CMSM 600, the micropore volume of $327.4 \mathrm{~cm}^{3}$ $\mathrm{kg}^{-1}$ is slightly higher $[68,69]$. The obtained mean pore widths are
Table 4

Structural parameters.

\begin{tabular}{lccccc}
\hline & \multicolumn{2}{l}{ Ionic liquid process } & & \multicolumn{2}{l}{ Viscose process [57] } \\
\cline { 2 - 3 } \cline { 6 - 6 } \cline { 5 - 6 } & CMSM 550 & CMSM 600 & & CMSM 550 & CMSM 600 \\
\hline$W_{0}\left(\mathrm{~cm}^{3} \mathrm{~kg}^{-1}\right)$ & 250.2 & 327.4 & & 274.2 & 322.5 \\
$E_{0}\left(\mathrm{~kJ} \mathrm{~mol}^{-1}\right)$ & 11.79 & 11.85 & & 12.30 & 12.71 \\
$l(\mathrm{~nm})$ & 0.711 & 0.700 & & 0.667 & 0.635 \\
\hline
\end{tabular}

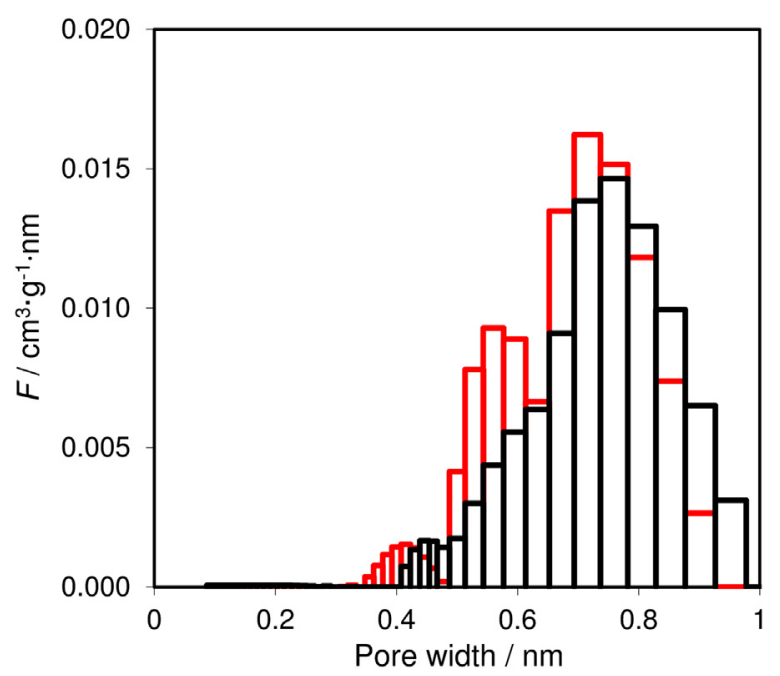

Fig. 11. Micropore size distribution of regenerated cellulose based-CMSM. Ionic liquid process: black line; viscose process: red line. Carbonization end temperature: $550{ }^{\circ} \mathrm{C}$ (For interpretation of the references to color in this figure legend, the reader is referred to the web version of this article.).

slightly higher when compared to other reported values [29,68-70]. Comparing the values with the values obtained for cellophane-based CMSM [57] (viscose process), it is possible to observe that these membranes have a higher mean pore width, which is in accordance with the obtained higher permeabilities as will be shown in Section 3.6.

The pore size distribution was obtained using the structure-based method proposed by Nguyen et al. for the determination of the micropore size distribution in carbonaceous materials [71,72]. Fig. 11 and Fig. 12 show the obtained micropore size distributions for CMSM 550

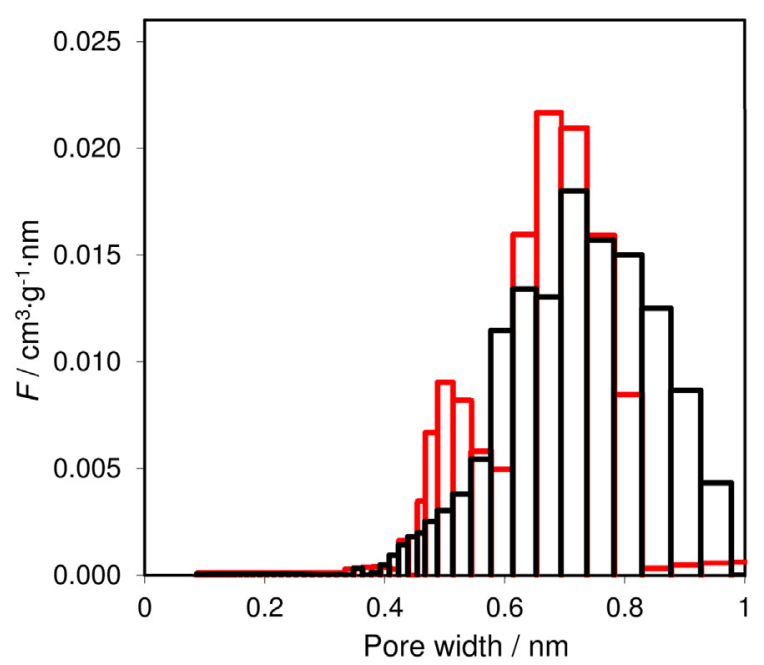

Fig. 12. Micropore size distribution of regenerated cellulose based-CMSM. Ionic liquid process: black line; viscose process: red line. Carbonization end temperature: $600{ }^{\circ} \mathrm{C}$ (For interpretation of the references to color in this figure legend, the reader is referred to the web version of this article.). 
Table 5

Permeabilities and ideal selectivities for regenerated cellulose-based CMSM at $25^{\circ} \mathrm{C}$.

\begin{tabular}{lcllll}
\hline Gas species & CMSM 550 & & & \multicolumn{2}{l}{ CMSM 600 } \\
\cline { 2 - 3 } \cline { 5 - 6 } \cline { 5 - 6 } & $\begin{array}{l}\text { Permeability } \\
\text { (barrer) }\end{array}$ & $\begin{array}{l}\text { Permselectivity } \\
\text { X/N }\end{array}$ & $\begin{array}{l}\text { Permeability } \\
\text { (barrer) }\end{array}$ & $\begin{array}{l}\text { Permselectivity } \\
\text { X/N }\end{array}$ \\
\hline $\mathrm{N}_{2}$ & 0.16 & - & 0.09 & - \\
$\mathrm{O}_{2}$ & 5.16 & 32.3 & 2.19 & 24.3 \\
$\mathrm{CO}_{2}$ & 13.4 & 83.8 & & 4.18 & 46.4 \\
$\mathrm{He}$ & 126 & 788 & 174 & 1993 \\
$\mathrm{H}_{2}$ & 206.0 & 1288 & 121 & 1344 \\
\hline
\end{tabular}

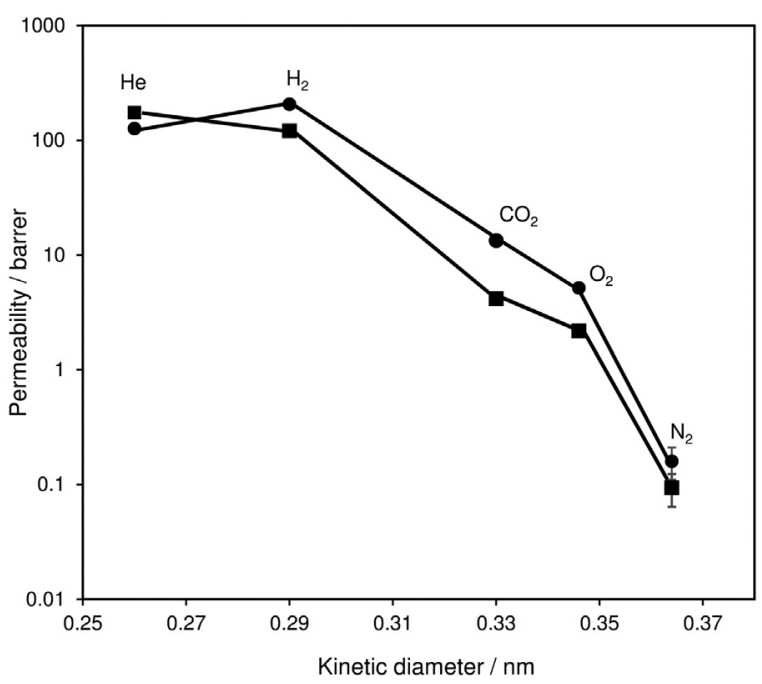

Fig. 13. Permeability as a function of the gas kinetic diameter for regenerated cellulose-based membranes carbonized at $\cdot 550{ }^{\circ} \mathrm{C}$ and $600{ }^{\circ} \mathrm{C}$, the variance bars of 3 reads were added. Lines were added for readability.

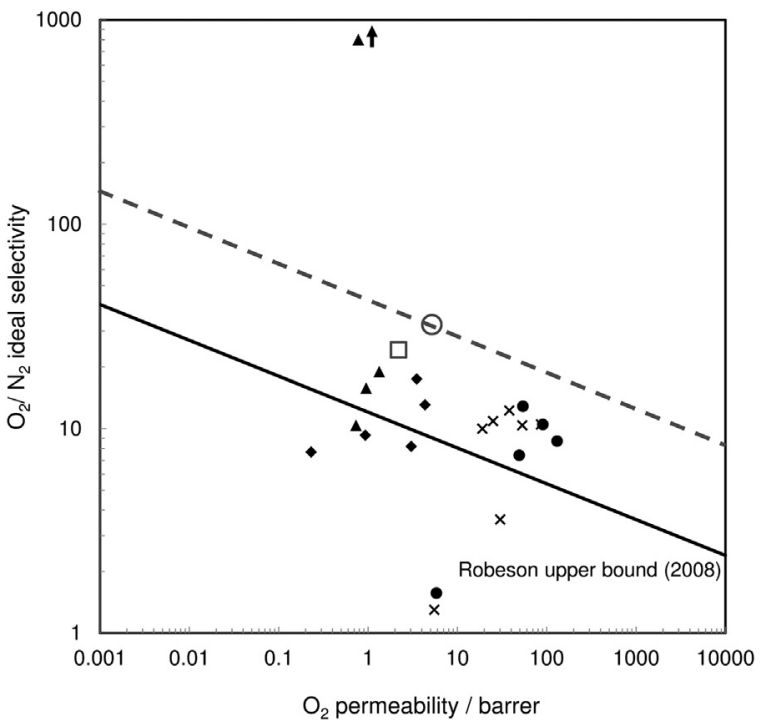

Fig. 14. Gas permeation results for $\mathrm{O}_{2} / \mathrm{N}_{2}$ in $\bigcirc$ CMSM 550, $\square$ CMSM 600 and reported cellulose-based CMSM $(\diamond[34] ; \cdot[33] ; \boldsymbol{\Delta}[36,57] ; \times[78])$ and comparison with the respective upper bound plot.

and CMSM 600, respectively, and a comparison with the PSD obtained for cellophane-based CMSM [57].

From Figs. 11 and 12, it can be seen that the carbon molecular sieve membranes prepared in this work at two different carbonization end temperatures present ultramicropores $(0.4-0.7 \mathrm{~nm}$ range) and

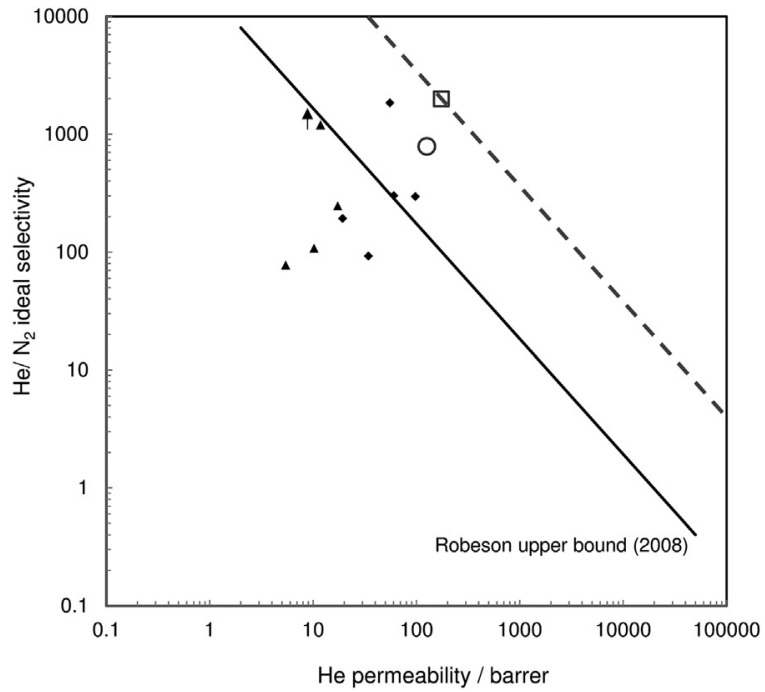

Fig. 15. Gas permeation results for $\mathrm{He} / \mathrm{N}_{2}$ in $\bigcirc$ CMSM 550 and $\square$ CMSM 600 and reported cellulose-based CMSM $(-[34] ; \mathbf{\Delta}[36,57] ; \times[78])$ and comparison with the respective upper bound plot.

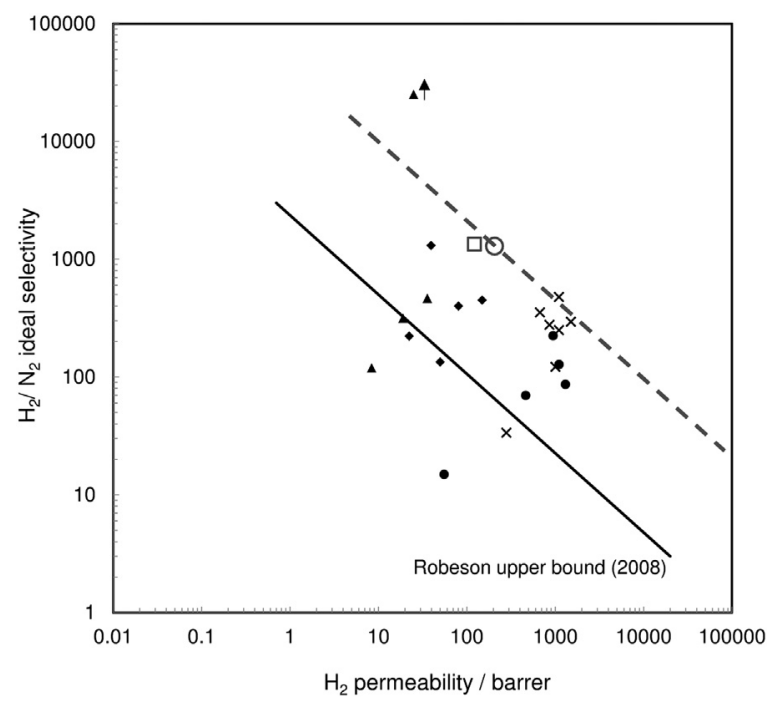

Fig. 16. Gas permeation results for $\mathrm{H}_{2} / \mathrm{N}_{2}$ in $\mathrm{O}$ CMSM 550 and $\square$ CMSM 600 and reported cellulose-based CMSM $(\diamond[34] ; \cdot[33] ; \boldsymbol{\Delta}[36,57] ; \times[78])$ and comparison with the respective upper bound plot.

micropores $(0.7-1 \mathrm{~nm})$. The regenerated cellulose-based CMSM (ionic liquid process) prepared at $550{ }^{\circ} \mathrm{C}$ and $600{ }^{\circ} \mathrm{C}$ present a micropore size distribution slightly shifted to the right, towards higher pore sizes when compared to the cellophane-based; once more, this is in accordance with the obtained higher permeabilities and low ideal selectivities (Section 3.6).

\subsection{Permeation experiments}

The membranes were tested for permeation using several probe species: nitrogen $(0.378 \mathrm{~nm})$, oxygen $(0.346 \mathrm{~nm})$, carbon dioxide $(0.335 \mathrm{~nm})$, hydrogen $(0.290 \mathrm{~nm})$ and helium $(0.260 \mathrm{~nm})-$ the values in brackets correspond to the kinetic diameter of the gases [70]. Table 5 presents the obtained permeabilities and ideal selectivities for the regenerated cellulose-based CMSM prepared at $550{ }^{\circ} \mathrm{C}$ and $600{ }^{\circ} \mathrm{C}$.

Fig. 13 shows the permeability towards several gas species against their kinetic diameter.

Carbon molecular sieve membranes comprise rigid micropore and ultramicropores regions and permeation through these membranes 


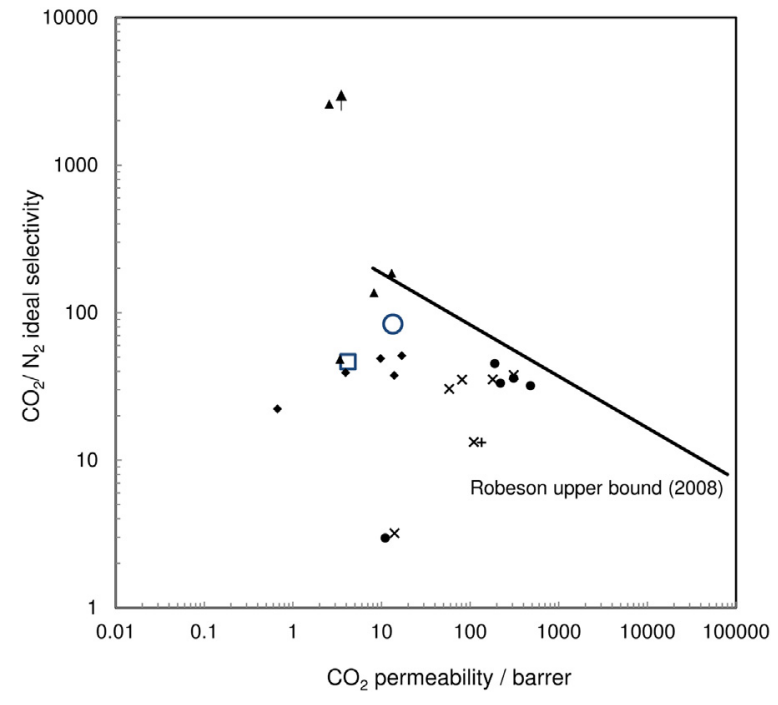

Fig. 17. Gas permeation results for $\mathrm{CO}_{2} / \mathrm{N}_{2}$ in $\bigcirc \mathrm{CMSM} 550$ and $\square \mathrm{CMSM} 600$ and reported cellulose-based CMSM $(\diamond[34] ; \cdot[33] ; \mathbf{\Delta}[36,57] ; \times[78] ;+[77])$ and comparison with the respective upper bound plot.

follows a sorption-diffusion mechanism. The micropores provide sorption sites (gas molecules hop from site to site due to a transmembrane concentration gradient) and ultramicropores provide diffusion restrictions with the ability of discriminate gas molecules based on their size and shape; therefore, ultramicropores control the transport behavior of carbon molecular sieve membranes and determine most of the observed selectivity $[73,74]$. From Fig. 13, it can be observed that the membrane permeability follows the kinetic diameter of the permeant species. Also, hydrogen with a larger kinetic diameter than helium, permeates faster for CMSM 550 samples; this fact has been reported by other authors [34,75] showing the extent of adsorption (larger for hydrogen than for helium). The effect of carbonization end temperature on the gas performance of regenerated cellulose-based CMSM is also demonstrated in Fig. 13 and Table 5. The samples carbonized at higher temperature (CMSM 600) have generally smaller gas permeation; for example, the membrane permeability towards nitrogen became around 1.8 times smaller when compared to CMSM 550 - rates - CMSM 550 have a larger mean pore width compared to CMSM 600 (Table 4). At $600{ }^{\circ} \mathrm{C}$, carbon atoms are rearranging into a tighter structure, by a sintering mechanism $[34,76]$. However, CMSM 600 have a larger volume of ultramicropores (Figs. 11 and 12), leading to a higher permeability to helium [29]. However, though this sample displays more pores they are smaller making the permeability of this sample to the other gases smaller than for sample CMSM 550.

The performance of a carbon membrane towards a separation is characterized by the gas permeability as well as the correspondent selectivity. In 2008, Robeson proposed a selectivity/permeability upper bound for representative binary gas separations performed with polymeric membranes. Figs. 14-17 illustrate the Robeson upper bounds for $\mathrm{O}_{2} / \mathrm{N}_{2}$ (Fig. 14), $\mathrm{He} / \mathrm{N}_{2}$ (Fig. 15), $\mathrm{H}_{2} / \mathrm{H}_{2}$ (Fig. 16) and $\mathrm{CO}_{2} / \mathrm{N}_{2}$ (Fig. 17), together with the results obtained in this work; a comparison with CMSM produced from other cellulosic precursors reported in literature $[33,34,36,57,77,78]$ is also included. For facilitating the comparison, a dashed line was drawn over the best sample of the present work, parallel to the Robeson line. All values below this line perform worse and vice-versa. Robeson upper bounds are broadly recognized as the state-ofthe-art curves for gas separation.

It can be observed that the CMSM prepared in this work are plotted above the upper bound for $\mathrm{O}_{2} / \mathrm{N}_{2}, \mathrm{He} / \mathrm{N}_{2}$ and $\mathrm{H}_{2} / \mathrm{N}_{2}$ separations. Moreover, when these membranes are compared to the reported cellulosic-based CMSM, (see dashed line) they show a better permeability/ permselectivity balance (except for the cellophane-based CMSM prepared in our previous work) for most of the studied gas separations.

\subsubsection{Relative humidity stability}

Permeation experiments in the presence of $75-77 \%$ RH were undertaken using the regenerated cellulose-based CMSM to determine its performance stability in the presence of water vapor. Table 6 shows the permeability of CMSM 550 and CMSM 600 samples to dry and humidified oxygen and nitrogen. Permeation data showed that humidity does not originate pore blockage for RH above ca. 30-40\% as reported for all carbon molecular sieve membranes [13,79]. For carbon membrane samples prepared at $550{ }^{\circ} \mathrm{C}$, the overall permeability increased ca. 1.6 times (the permeability to oxygen stays roughly constant); for carbon membrane samples prepared at $600{ }^{\circ} \mathrm{C}$, the overall permeability increased $c a$. 2.7 times. This increase is due to the very fast permeation of water vapor that occurs due to the membrane's high hidrophilicity. Previous studies by the authors demonstrated that the high hydrophilicity is characteristic of regenerated cellulose-based CMSM [57].

\section{Conclusions}

Carbon molecular sieve membranes with high separation performance and stability in the presence of humidity were successfully prepared in a single carbonization step, without need for pre nor post treatments steps. The carbon membranes were prepared from regenerated cellulose, a renewable low cost precursor, using an ionic liquid as cellulose solvent and spin coating for casting the precursor film. Ionic liquids are environmentally friendly and more efficient solvents than current methodologies to dissolve and process cellulose. This was the first time that regenerated cellulose films produced through an ionic liquid process were studied for preparation of CMSM. The permeability versus kinetic diameter towards nitrogen, carbon dioxide, oxygen, hydrogen and helium exhibited a molecular sieve mechanism for the prepared membranes. The effect of carbonization end temperature was assessed, and better separation performances were found for CMSM 550 sample, carbonized in an inert atmosphere at $550{ }^{\circ} \mathrm{C}$. The Robeson upper bound for polymeric membranes was overtaken by the prepared membranes regarding $\mathrm{O}_{2} / \mathrm{N}_{2}, \mathrm{He} / \mathrm{N}_{2}$ and $\mathrm{H}_{2} / \mathrm{N}_{2}$ separations.

The produced carbon molecular sieve membranes are stable and have a great potential for gas separation; therefore, they might be considered in relevant industrial applications such as separation of nitrogen from air, air dehumidification and separation of hydrogen from syngas.

\section{Acknowledgments}

S.C. Rodrigues is grateful to the Portuguese Foundation for Science and Technology (FCT) for the doctoral grant (reference SFRH/BD/

Table 6

Permeability of CMSM 550 and CMSM 600 to dry and humidified oxygen and nitrogen.

\begin{tabular}{|c|c|c|c|c|c|}
\hline \multirow[t]{2}{*}{ Sample } & \multirow[t]{2}{*}{$\mathrm{RH}(\%)$} & \multicolumn{2}{|l|}{ Dry feed } & \multicolumn{2}{|l|}{ Humidified feed } \\
\hline & & Permeability to $\mathrm{O}_{2}$ (barrer) & Permeability to $\mathrm{N}_{2}$ (barrer) & Permeability to humidified $\mathrm{O}_{2}$ (barrer) & Permeability to humidified $\mathrm{N}_{2}$ (barrer) \\
\hline CMSM 550 & $75-77$ & 5.16 & 0.16 & 8.47 & 1.33 \\
\hline CMSM 600 & $75-77$ & 2.19 & 0.09 & 5.96 & 0.85 \\
\hline
\end{tabular}


93779/2013) supported by funding POPH/FSE. M. Andrade is thankful to POCI-01-0145-FEDER-006939 (Laboratory for Process Engineering, Environment, Biotechnology and Energy - UID/EQU/00511/2013) funded by the European Regional Development Fund (ERDF), through COMPETE2020 - Programa Operacional Competitividade e Internacionalização (POCI) and by national funds, through FCT Fundação para a Ciência e a Tecnologia and NORTE-01-0145-FEDER-000005 - LEPABE-2-ECO-INNOVATION, supported by North Portugal Regional Operational Programme (NORTE 2020), under the Portugal 2020 Partnership Agreement, through the European Regional Development Fund (ERDF) for the fellowship grant. The authors are thankful to Innovia Films Ltd. for generously providing wood pulp.

\section{References}

[1] Q. Liu, T. Wang, H. Guo, C. Liang, S. Liu, Z. Zhang, Y. Cao, D.S. Su, J. Qiu, Controlled synthesis of high performance carbon/zeolite T composite membrane materials for gas separation, Microporous Mesoporous Mater. 120 (2009) 460-466.

[2] X. Ma, B.K. Lin, X. Wei, J. Kniep, Y.S. Lin, Gamma-alumina supported carbon molecular sieve membrane for propylene/propane separation, Ind. Eng. Chem. Res. 52 (2013) 4297-4305.

[3] T.C. Merkel, H. Lin, X. Wei, R. Baker, Power plant post-combustion carbon dioxide capture: an opportunity for membranes, J. Membr. Sci. 359 (2010) 126-139.

[4] R. Faiz, K. Li, Polymeric membranes for light olefin/paraffin separation, Desalination 287 (2012) 82-97.

[5] W. Wei, G. Qin, H. Hu, L. You, G. Chen, Preparation of supported carbon molecular sieve membrane from novolac phenol-formaldehyde resin, J. Membr. Sci. 303 (2007) 80-85.

[6] A.F. Ismail, L.I.B. David, A review on the latest development of carbon membranes for gas separation, J. Membr. Sci. 193 (2001) 1-18.

[7] P.S. Tin, T.-S. Chung, S. Kawi, M.D. Guiver, Novel approaches to fabricate carbon molecular sieve membranes based on chemical modified and solvent treated polyimides, Microporous Mesoporous Mater. 73 (2004) 151-160.

[8] M. Kiyono, P.J. Williams, W.J. Koros, Effect of pyrolysis atmosphere on separation performance of carbon molecular sieve membranes, J. Membr. Sci. 359 (2010) $2-10$.

[9] P.J. Williams, W.J. Koros, Gas separation by carbon membranes, in: N.N. Li, A.G. Fane, W.S.W. Ho, T. Matsuura (Eds.), Advanced Membrane Technology and Applications, John Wiley \& Sons, New Jersey, 2008, pp. 599-627.

[10] A.F. Ismail, D. Rana, T. Matsuura, H.C. Foley, Carbon-based Membranes for Separation Processes, first ed., Springer, New York, 2011.

[11] M.A.L. Tanco, D.A.P. Tanaka, Recent Advances on carbon molecular sieve membranes (CMSMs) and reactors, Processes 4 (2016) 1-29.

[12] A. Mendes, F.D. Magalhães, C.A.V. Costa, New trends on membrane science, in: W.C. Conner, J. Fraissard (Eds.), Fluid Transport in Nanoporous Materials, Springer, The Netherlands, 2006, p. 686 .

[13] C.W. Jones, W.J. Koros, Characterization of ultramicroporous carbon membranes with humidified feeds, Ind. Eng. Chem. Res. 34 (1995) 158-163.

[14] I. Menendez, A.B. Fuertes, Aging of carbon membranes under different environments, Carbon 39 (2001) 733-740

[15] S. Lagorsse, M.C. Campo, F.D. Magalhães, A. Mendes, Water adsorption on carbon molecular sieve membranes: experimental data and isotherm model, Carbon 43 (2005) 2769-2779.

[16] K.M. Steel, W.J. Koros, An investigation of the effects of pyrolysis parameters on gas separation properties of carbon materials, Carbon 43 (2005) 1843-1856.

[17] X. Ma, R. Swaidan, B. Teng, H. Tan, O. Salinas, E. Litwiller, Y. Han, I. Pinnau, Carbon molecular sieve gas separation membranes based on an intrinsically microporous polyimide precursor, Carbon 62 (2013) 88-96.

[18] X. Ning, W.J. Koros, Carbon molecular sieve membranes derived from Matrimid" polyimide for nitrogen/methane separation, Carbon 66 (2014) 511-522.

[19] O. Salinas, X. Ma, E. Litwiller, I. Pinnau, High-performance carbon molecular sieve membranes for ethylene/ethane separation derived from an intrinsically microporous polyimide, J. Membr. Sci. 500 (2016) 115-123.

[20] Y.-J. Fu, C.-C. Hu, D.-W. Lin, H.-A. Tsai, S.-H. Huang, W.-S. Hung, K.-R. Lee, J. Y. Lai, Adjustable microstructure carbon molecular sieve membranes derived from thermally stable polyetherimide/polyimide blends for gas separation, Carbon 113 (2017) 10-17.

[21] L.I.B. David, A.F. Ismail, Influence of the thermastabilization process and soak time during pyrolysis process on the polyacrylonitrile carbon membranes for $\mathrm{O}_{2} / \mathrm{N}_{2}$ separation, J. Membr. Sci. 213 (2003) 285-291.

[22] Y.D. Chen, R.T. Yang, Preparation of carbon molecular sieve membrane and diffusion of binary mixtures in the membrane, Ind. Eng. Chem. Res. 33 (1994) $3146-3153$

[23] C. Song, T. Wang, X. Wang, J. Qiu, Y. Cao, Preparation and gas separation properties of poly(furfuryl alcohol)-based C/CMS composite membranes, Sep. Purif. Technol. 58 (2008) 412-418.

[24] M.A.L. Tanco, D.A.P. Tanaka, S.C. Rodrigues, M. Texeira, A. Mendes, Compositealumina-carbon molecular sieve membranes prepared from novolac resin and boehmite. Part I: preparation, characterization and gas permeation studies, Int. J. Hydrog. Energy 40 (2015) 5653-5663.
[25] A.B. Fuertes, I. Menendez, Separation of hydrocarbon gas mixtures using phenolic resin-based carbon membranes, Sep. Purif. Technol. 28 (2002) 29-41.

[26] M. Teixeira, M.C. Campo, D.A.P. Tanaka, M.A.L. Tanco, C. Magen, A. Mendes, Composite phenolic resin-based carbon molecular sieve membranes for gas separation, Carbon 49 (2011) 4348-4358.

[27] W. Zhou, M. Yoshino, H. Kita, K.-i. Okamoto, Carbon molecular sieve membranes derived from phenolic resin with a pendant sulfonic acid group, Ind. Eng. Chem. Res. 40 (2001) 4801-4807.

[28] M. Teixeira, S.C. Rodrigues, M. Campo, D.A. Pacheco Tanaka, M.A. Llosa Tanco, L.M. Madeira, J.M. Sousa, A. Mendes, Boehmite-phenolic resin carbon molecular sieve membranes-permeation and adsorption studies, Chem. Eng. Res. Des. 92 (2014) 2668-2680.

[29] S.C. Rodrigues, R. Whitley, A. Mendes, Preparation and characterization of carbon molecular sieve membranes based on resorcinol-formaldehyde resin, J. Membr. Sci. 459 (2014) 207-216.

[30] M. Yoshimune, T. Yamamoto, M. Nakaiwa, K. Haraya, Preparation of highly mesoporous carbon membranes via a sol-gel process using resorcinol and formaldehyde, Carbon 46 (2008) 1031-1036.

[31] Y.-R. Dong, M. Nakao, N. Nishiyama, Y. Egashira, K. Ueyama, Gas permeation and pervaporation of water/alcohols through the microporous carbon membranes prepared from resorcinol/formaldehyde/quaternary ammonium compounds, Sep. Purif. Technol. 73 (2010) 2-7.

[32] S. Tanaka, T. Yasuda, Y. Katayama, Y. Miyake, Pervaporation dehydration performance of microporous carbon membranes prepared from resorcinol/formaldehyde polymer, J. Membr. Sci. 379 (2011) 52-59.

[33] J.A. Lie, M.-B. Hägg, Carbon membranes from cellulose: synthesis, performance and regeneration, J. Membr. Sci. 284 (2006) 79-86.

[34] M.C. Campo, F.D. Magalhães, A. Mendes, Carbon molecular sieve membranes from cellophane paper, J. Membr. Sci. 350 (2010) 180-188.

[35] M.C. Campo, F.D. Magalhães, A. Mendes, Separation of nitrogen from air by carbon molecular sieve membranes, J. Membr. Sci. 350 (2010) 139-147.

[36] A. Mendes, M. Andrade, M. Boaventura, S.C. Rodrigues, A carbon molecular sieve membrane, method of preparation and uses thereof, Patent WO 2017068517 A1, 2017.

[37] H. Wang, G. Gurau, R.D. Rogers, Ionic liquid processing of cellulose, Chem. Soc. Rev. 41 (2012) 1519-1537.

[38] J. Pang, X. Liu, X. Zhang, Y. Wu, R. Sun, Fabrication of cellulose film with enhanced mechanical properties in ionic liquid 1-allyl-3-methylimidaxolium chloride (AmimCl), Materials 6 (2013) 1270.

[39] B. Ma, A. Qin, X. Li, C. He, Preparation of cellulose hollow fiber membrane from bamboo pulp/1-butyl-3-methylimidazolium chloride/dimethylsulfoxide system, Ind. Eng. Chem. Res. 52 (2013) 9417-9421.

[40] Z.C. Zhang, Catalytic transformation of carbohydrates and lignin in ionic liquids, WIREs Energy Environ. 2 (2013) 655-672.

[41] S. Mahmoudian, M.U. Wahit, A.F. Ismail, A.A. Yussuf, Preparation of regenerated cellulose/montmorillonite nanocomposite films via ionic liquids, Carbohydr. Polym. 88 (2012) 1251-1257.

[42] S. Livazovic, Z. Li, A.R. Behzad, K.V. Peinemann, S.P. Nunes, Cellulose multilayer membranes manufacture with ionic liquid, J. Membr. Sci. 490 (2015) 282-293.

[43] A. Pinkert, K.N. Marsh, S. Pang, M.P. Staiger, Ionic liquids and their interaction with cellulose, Chem. Rev. 109 (2009) 6712-6728.

[44] H.-Z. Chen, N. Wang, L.-Y. Liu, Regenerated cellulose membrane prepared with ionic liquid 1-butyl-3-methylimidazolium chloride as solvent using wheat straw, J. Chem. Technol. Biotechnol. 87 (2012) 1634-1640.

[45] M.T. Clough, K. Geyer, P.A. Hunt, S. Son, U. Vagt, T. Welton, Ionic liquids: not always innocent solvents for cellulose, Green Chem. 17 (2015) 231-243.

[46] B. Kosan, C. Michels, F. Meister, Dissolution and forming of cellulose with ionic liquids, Cellulose 15 (2008) 59-66.

[47] J.-H. Pang, X. Liu, M. Wu, Y.-Y. Wu, X.-M. Zhang, R.-C. Sun, Fabrication and characterization of regeneratedcellulose films using different ionic liquids, J. Spectrosc. 2014 (2014) 1-8.

[48] F. Hoelkeskamp, Process for production of cuprammonium cellulose articles, US patent 3110546 A, 1963.

[49] T. Welton, Room-temperature ionic liquids. Solvents for synthesis and catalysis, Chem. Rev. 99 (1999) 2071-2084.

[50] S. Mallakpour, M. Dinari, Ionic liquid as green solvents: progress and prospects, in: A. Mohammad Inamuddin (Ed.), Green Solvents II. Properties and Applications of Ionic Liquids, Springer, Dordrecht, 2012, p. 506.

[51] K.M. Gupta, J. Jiang, Cellulose dissolution and regeneration in ionic liquids: computational perspective, Chem. Eng. Sci. 121 (2015) 180-189.

[52] J. Wang, J. Luo, S. Feng, H. Li, Y. Wan, X. Zhang, Recent development of ionic liquid membranes, Green. Energy Environ. 1 (2016) 43-61.

[53] M. Ottaway, Use of thermogravimetry for proximate analysis of coals and cokes, Fuel 61 (1982) 713-716.

[54] D. Ferreira, R. Magalhães, P. Taveira, A. Mendes, Effective adsorption equilibrium isotherms and breakthroughs of water vapor and carbon dioxide on different adsorbents, Ind. Eng. Chem. Res. 50 (2011) 10201-10210.

[55] J.C. Santos, F.D. Magalhães, A. Mendes, Contamination of zeolites used in oxygen production by PSA: effects of water and carbon dioxide, Ind. Eng. Chem. Res. 47 (2008) 6197-6203.

[56] L.M. Robeson, Correlation of separation factor versus permeability for polymeric membranes, J. Membr. Sci. 62 (1991) 165-185.

[57] S.C. Rodrigues, M. Andrade, F.D. Magalhães, A. Mendes, Carbon membranes with extremely high separation performance and stability, unspublished results.

[58] M. Sevilla, A.B. Fuertes, The production of carbon materials by hydrothermal carbonization of cellulose, Carbon 47 (2009) 2281-2289. 
[59] C.S.R. Freire, A.J.D. Silvestre, C.P. Neto, M.N. Belgacem, A. Gandini, Controlled heterogeneous modification of cellulose fibers with fatty acids: effect of reaction conditions on the extent of esterification and fiber properties, J. Appl. Polym. Sci. 100 (2006) 1093-1102.

[60] Y.-J. Fu, K.-S. Liao, C.-C. Hu, K.-R. Lee, J.-Y. Lai, Development and characterization of micropores in carbon molecular sieve membrane for gas separation, Microporous Mesoporous Mater. 143 (2011) 78-86.

[61] C. Araujo-Andrade, F. Ruiz, J.R. Martínez-Mendoza, H. Terrones, Infrared and Raman spectra, conformational stability, ab initio calculations of structure, and vibrational assignment of $\alpha$ and $\beta$ glucose, J. Mol. Struct.: THEOCHEM 714 (2005) 143-146.

[62] J. Ibarra, E. Muñoz, R. Moliner, FTIR study of the evolution of coal structure during the coalification process, Org. Geochem. 24 (1996) 725-735.

[63] D. Ciolacu, F. Ciocacu, V.I. Popa, Amorphous cellulose - structure and characterization, Cellul. Chem. Technol. 45 (2011) 13-21.

[64] J.M. Chalmers, P.R. Griffiths (Eds.), Handbook of Vibrational Spectroscopy, John Wiley \& Sons, Chichester, 2002.

[65] B.M. Kabyemela, T. Adschiri, R.M. Malaluan, K. Arai, Glucose and fructose decomposition in subcritical and supercritical water: detailed reaction pathway, mechanisms and kinetics, Ind. Eng. Chem. Res. 38 (1999) 2888-2895.

[66] A.C. Lua, T. Yang, Effect of activation temperature on the textural and chemical properties of potassium hydroxide activated carbon prepared from pistachio-nut shell, J. Colloid Interface Sci. 274 (2004) 594-601.

[67] N.D. Hutson, R.T. Yang, Theoretical basis for the Dubinin-Radushkevitch (D-R) adsorption isotherm equation, Adsorption 3 (1997) 189-195.

[68] D. Cazorla-Amorós, J. Alcañiz-Monge, M.A. de la Casa-Lillo, A. Linares-Solano, $\mathrm{CO}_{2}$ as an adsorptive to characterize carbon molecular sieves and activated carbons, Langmuir 14 (1998) 4589-4596.

[69] S. Lagorsse, F.D. Magalhães, A. Mendes, Carbon molecular sieve membranes: sorption, kinetic and structural characterization, J. Membr. Sci. 241 (2004) 275-287.

[70] M. Teixeira, M. Campo, D.A. Tanaka, M.A. Tanco, C. Magen, A. Mendes, Carbon- $\mathrm{Al}_{2} \mathrm{O}_{3}-\mathrm{Ag}$ composite molecular sieve membranes for gas separation, Chem. Eng. Res. Des. 90 (2012) 2338-2345.

[71] C. Nguyen, D.D. Do, K. Haraya, K. Wang, The structural characterization of carbon molecular sieve membrane (CMSM) via gas adsorption, J. Membr. Sci. 220 (2003) 177-182.

[72] C. Nguyen, D.D. Do, Adsorption of supercritical gases in porous media: determination of micropore size distribution, J. Phys. Chem. B 103 (1999) 6900-6908.

[73] S. Fu, E.S. Sanders, S. Kulkarni, Y.-H. Chu, G.B. Wenz, W.J. Koros, The significance of entropic selectivity in carbon molecular sieve membranes derived from 6FDA/ DETDA:DABA(3:2) polyimide, J. Membr. Sci. 539 (2017) 329-343.

[74] M. Rungta, L. Xu, W.J. Koros, Structure-performance characterization for carbon molecular sieve membranes using molecular scale gas probes, Carbon 85 (2015) 429-442.

[75] H. Suda, K. Haraya, Gas permeation through micropores of carbon molecular sieve membranes derived from kapton polyimide, J. Phys. Chem. B 101 (1997) 3988-3994.

[76] J. Koresh, A. Soffer, Study of molecular sieve carbons. Part 1.-Pore structure, gradual pore opening and mechanism of molecular sieving, J. Chem. Soc., Faraday Trans. 1 (76) (1980) 2457-2471.

[77] X. He, J.A. Lie, E. Sheridan, M.-B. Hägg, Preparation and characterization of hollow fiber carbon membranes from cellulose acetate precursors, Ind. Eng. Chem. Res. 50 (2011) 2080-2087.

[78] J.A. Lie, M.-B. Hägg, Carbon membranes from cellulose and metal loaded cellulose, Carbon 43 (2005) 2600-2607.

[79] S. Lagorsse, F.D. Magalhães, A. Mendes, Aging study of carbon molecular sieve membrabes, J. Membr. Sci. 310 (2008) 494-502. 